\title{
Monte Carlo-based subgrid parameterization of vertical velocity and stratiform cloud microphysics in ECHAM5.5-HAM2
}

\author{
J. Tonttila ${ }^{1,2}$, P. Räisänen ${ }^{1}$, and H. Järvinen ${ }^{2}$ \\ ${ }^{1}$ Finnish Meteorological Institute, P.O. Box 503, 00101, Helsinki, Finland \\ ${ }^{2}$ Division of Atmospheric Sciences, Department of Physics, University of Helsinki, 00014, Helsinki, Finland \\ Correspondence to: J. Tonttila (juha.tonttila@ fmi.fi)
}

Received: 4 February 2013 - Published in Atmos. Chem. Phys. Discuss.: 27 February 2013

Revised: 6 June 2013 - Accepted: 23 June 2013 - Published: 6 August 2013

\begin{abstract}
A new method for parameterizing the subgrid variations of vertical velocity and cloud droplet number concentration (CDNC) is presented for general circulation models (GCMs). These parameterizations build on top of existing parameterizations that create stochastic subgrid cloud columns inside the GCM grid cells, which can be employed by the Monte Carlo independent column approximation approach for radiative transfer. The new model version adds a description for vertical velocity in individual subgrid columns, which can be used to compute cloud activation and the subgrid distribution of the number of cloud droplets explicitly. Autoconversion is also treated explicitly in the subcolumn space. This provides a consistent way of simulating the cloud radiative effects with two-moment cloud microphysical properties defined at subgrid scale. The primary impact of the new parameterizations is to decrease the CDNC over polluted continents, while over the oceans the impact is smaller. Moreover, the lower CDNC induces a stronger autoconversion of cloud water to rain. The strongest reduction in CDNC and cloud water content over the continental areas promotes weaker shortwave cloud radiative effects (SW CREs) even after retuning the model. However, compared to the reference simulation, a slightly stronger SW CRE is seen e.g. over mid-latitude oceans, where CDNC remains similar to the reference simulation, and the in-cloud liquid water content is slightly increased after retuning the model.
\end{abstract}

\section{Introduction}

The interplay between aerosols and clouds is regarded as a major uncertainty in climate prediction and modelling. Besides their direct effects on radiation, aerosols can affect the global radiation budget indirectly by acting as condensation nuclei for cloud droplets, which makes clouds and their radiative properties susceptible to changes in the aerosol size distribution and particle properties. Moreover, aerosols also have an influence on cloud dynamics by altering precipitation efficiency (Lohmann and Feichter, 2005).

The physical link between aerosol particles and cloud droplet formation in the current paradigm of simulating cloud droplet formation is the vertical velocity of an ascending air parcel, since it affects the saturation ratio of water vapour through adiabatic cooling. The current state-of-theart cloud activation parameterizations (e.g. Abdul-Razzak and Ghan, 2000; Fountoukis and Nenes, 2005; Ming et al., 2006; Khvorostyanov and Curry, 2009) rely on this assumption and can solve the critical radius for aerosol particles, given the maximum supersaturation, using the Koehler equation (Ghan et al., 2011). When aerosol size distribution is known, the critical radius yields the concentration of cloud condensation nuclei $(\mathrm{CCN})$ and, thus, the number of cloud droplets (Abdul-Razzak et al., 1998; Ghan et al., 2011). From the global modelling perspective, one of the long-lived challenges has been constructing a robust representation of the vertical velocity for cloud activation. Turbulent variability of vertical velocity has a strong impact on the number of cloud droplets in stratiform clouds, and it takes place at scales considerably smaller than the, typically, rather large grid spacing (on the order of 100-200 km) of global general circulation models (GCMs). Therefore, parameterizations are needed to account for the subgrid-scale variations of vertical velocity, i.e. the fluctuations of vertical velocity inside the model grid box around the resolved mean value. Several different approaches have been developed for these parameterizations in GCMs (Ghan et al., 1997; Lohmann et al., 1999; Hoose et al., 2010). 
In this paper, we present a new approach to account for the subgrid variations in vertical velocity and its implications on cloud droplet number concentration (CDNC) and cloud radiative effects. Our work builds on top of the ECHAM5.5HAM2 aerosol-climate model which has been augmented with a stochastic cloud generator (SCG; Räisänen et al., 2004) and the Monte Carlo Independent Column Approximation radiation scheme (McICA; Pincus et al., 2003). In operation, the SCG divides a GCM grid column into an ensemble of cloudy subgrid columns which can be used directly by the McICA radiation scheme. Implementation of the SCG and McICA to ECHAM5 has been documented and evaluated in several studies (Räisänen et al., 2007, 2008; Räisänen and Järvinen, 2010).

Although the SCG can generate horizontally inhomogeneous cloud condensate amount for the subgrid columns, this framework has been constrained by the lack of information on the subgrid variability of CDNC that, until now, has been assumed horizontally homogeneous for GCM grid cells. The goal of this work is to remove this constraint. When both the cloud condensate amount and CDNC are described in each subgrid column separately, the direct coupling with the McICA radiation scheme provides a consistent way of representing the cloud radiative effects at subgrid scale without the need to average the subgrid cloud properties back to GCM scale between the processes. To achieve this goal, a new parameterization for vertical velocity in the subgrid cloudy columns is implemented, and it is coupled with the cloud droplet activation of aerosols and cloud microphysics. While aerosols also influence ice clouds, the current paper focuses on processes involving only warm (i.e. liquid-phase) clouds.

Our work will be presented as follows. Section 2 gives the model description for the ECHAM5.5-HAM2 aerosolclimate model, while Sect. 3 presents the implementation of the new parameterized subgrid components and modifications to the model configuration. Simple test runs are performed, for which experimental details are outlined in Sect. 4. Afterwards, results and model evaluation are presented in Sect. 5. Discussion and conclusions are given in Sects. 6 and 7.

\section{Model description}

Our baseline modelling system comprises the global atmospheric aerosol-climate model ECHAM5.5-HAM2. In ECHAM5.5 (Roeckner et al., 2003, 2006), the model dynamics are described in spectral space with spherical harmonics, while the model physics are calculated in grid-point space. The physical parameterizations in the model, including those representing turbulence, deep convection, stratiform cloud properties, gravity wave drag and surface properties, are invoked every time step. Parameterizations controlling radiation are called every two hours.
HAM2 (Zhang et al., 2012) is an interactive aerosol model that describes the evolution of the atmospheric aerosol population, accounting for what are presumably the five most important particle compositions (dust, black carbon, sulphate, organic carbon and sea salt; the secondary organic aerosol scheme by O'Donnell et al. (2011) is active in our model).

The aerosol size distribution is represented by 7 lognormal modes (the M7-module; Vignati et al., 2004). The dynamically described aerosol environment is coupled with the stratiform cloud microphysics scheme in ECHAM5 (Lohmann and Roeckner, 1996; Lohmann et al., 2007), where cloud droplet activation is described by Abdul-Razzak and Ghan (2000) and autoconversion of cloud droplets to rain is parameterized according to Khairoutdinov and Kogan (2000).

In addition, we have augmented our model configuration with two components: (1) a SCG (Räisänen et al., 2004) and (2) the McICA (Pincus et al., 2003) for radiative transfer. The SCG is a statistical algorithm that creates subgrid-scale columns (referred to as "subcolumns" from here on) to represent inhomogeneous cloud structure (cloud cover and cloud condensate) inside the GCM grid column. Another difference to the default settings of ECHAM5.5-HAM2 is that the Tompkins (2002) cloud scheme is active in our model. This is essential because statistical information about the subgrid variability of the total water mixing ratio is carried within the Tompkins scheme, eventually enabling the generation of the cloudy subcolumns, as described in detail in Räisänen et al. (2007).

The McICA radiation scheme uses the parameterizations by Mlawer et al. (1997) for longwave (LW) radiation, and Fouquart and Bonnel (1980) and Cagnazzo et al. (2007) for shortwave (SW) radiation. The scheme operates by drawing random samples from the ensemble of subcolumns created by the SCG, using a different column for each term in the spectral integration.

\section{Subgrid vertical velocity and cloud microphysics}

\subsection{Principle}

The stratiform cloud microphysics scheme, comprising prognostic equations for cloud water content and CDNC (Lohmann et al., 2007), is modified following three waypoints: (1) a parameterization for subcolumn vertical velocity $w$ is implemented, (2) the parameterization for cloud droplet activation (Abdul-Razzak and Ghan, 2000) is modified for subcolumns and (3) the key cloud microphysical processes controlling CDNC are treated explicitly in the subcolumn space.

A flowchart of the subgrid treatment of warm clouds is given schematically in Fig. 1, where different processes are presented in chronological order starting from the top of the figure. In addition, lines between the processes indicate the scale at which the computations take place: a single thick 


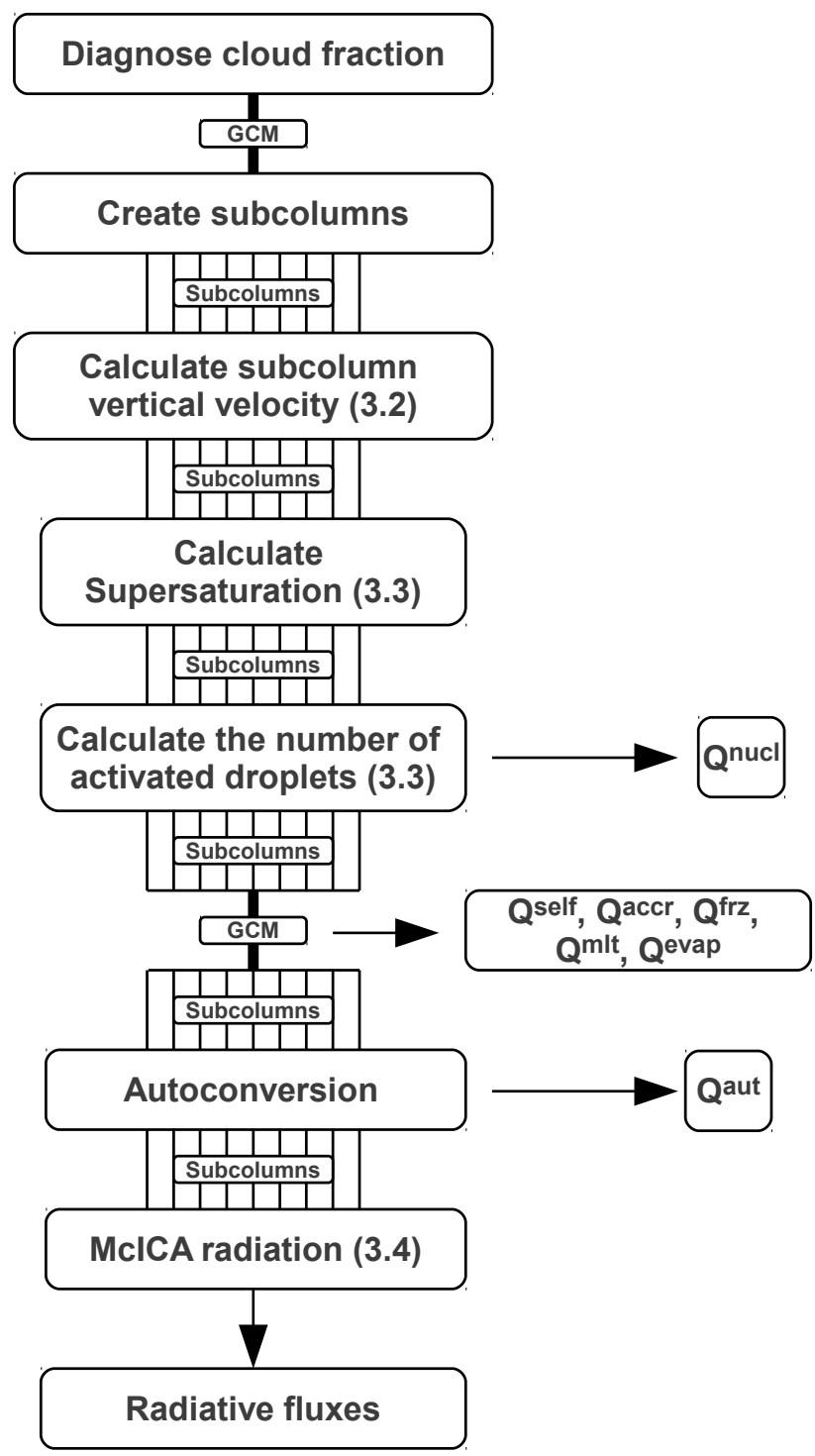

Fig. 1. Schematic description of the workflow in the new model version with subgrid treatment for vertical velocity and cloud microphysical properties. Thick black lines labelled as "GCM" refer to GCM grid-scale computation, while thin lines labelled as "subcolumns" refer to subgrid representation of processes. Arrows describe the most important outputs from the parameterized processes (all given in GCM grid scale). Numbers next to some of the processes refer to the section of this paper giving further details.

line describes GCM-scale processes, while thin lines indicate processes operating in the subcolumn space. Starting from the top of Fig. 1, the Tompkins (2002) cloud cover scheme is used to diagnose the GCM-scale cloud fraction, and statistical properties related to the distribution of cloud condensate amount inside the GCM grid cell. Next, cloudy subcolumns are created by the SCG, based on information provided by the Tompkins (2002) scheme as described in Räisänen et al. (2007). A cloud fraction of 0 or 1 is assigned to each model layer of the subcolumns, with condensate amount varying between the subcolumns. This is followed by the diagnosis of the subcolumn cloud-base vertical velocity $w$ by the new parameterization, which is then used to calculate the maximum supersaturation $\left(S^{\max }\right)$ for cloud activation. This in turn enables the calculation of CDNC in the cloudy subcolumns. Since the subcolumns are stochastic and re-generated for each time step, the subcolumn CDNC distribution is treated as a diagnostic property. Prognostic CDNC is retained at GCM scale as (Lohmann et al., 1999):

$$
\frac{\partial N}{\partial t}=Q^{\text {nucl }}-Q^{\text {aut }}-Q^{\text {self }}-Q^{\text {frz }}+Q^{\text {mlt }}-Q^{\text {evap }}-Q^{\text {accr }} .
$$

Here, and in all subsequent equations, $\mathrm{CDNC}$ is denoted as $N$. $Q^{\text {nucl }}$ and $Q^{\text {mlt }}$ represent source terms due to droplet nucleation and melting of ice particles, respectively. The sink terms are given by $Q^{\text {aut }}, Q^{\text {self }}, Q^{\text {frz }}, Q^{\text {evap }}$ and $Q^{\text {accr }}$ (autoconversion of cloud droplets to rain, self-collection of cloud droplets, freezing, evaporation and accretion of cloud droplets by rain or snow, respectively). The terms on the right-hand side of Eq. (1) represent GCM-scale values, although subcolumn-scale properties can be used to compute them.

To save on computational cost, in addition to cloud activation $\left(Q^{\text {nucl }}\right)$, only autoconversion $\left(Q^{\text {aut }}\right)$ is treated explicitly in the subcolumn space, as shown in Fig. 1. These processes comprise most of the non-linearities affecting the CDNC and are therefore chosen for the explicit subgrid treatment. The remaining processes comprise mostly phase changes depending on temperature and are thus assumed to affect only the mean of the CDNC in the GCM grid cell. It is assumed that the fractional change in CDNC caused by these processes is equally large for all subcolumns. Thus, the subcolumn CDNC values are scaled with the fractional change in the GCM-grid mean, so that the subcolumn ensemble mean always matches the GCM-grid mean. After the cloud microphysical calculations have been completed, the subcolumn values of cloud fraction $(0 / 1)$, cloud condensate amount and CDNC are employed in the McICA radiation calculations, providing the GCM grid column mean radiative fluxes for shortwave and longwave radiation. Next, key features related to the subcolumn vertical velocity parameterization, cloud activation and CDNC are presented in more detail.

\subsection{Subcolumn parameterization for vertical velocity}

A simple Monte Carlo-type sampling is used to diagnose subcolumn vertical velocity for cloud activation $w_{j, k}$ (the indices are used to emphasize subcolumn values $-j$ denotes the subcolumn index and $k$ denotes model level). A probability density function (PDF) is utilized to represent the subgridscale variability in $w$. Instead of integrating the cloud droplet activation over the vertical velocity PDF for a mean CDNC, positive vertical velocity samples are drawn from the PDF, providing cloud-base vertical velocity in each subcolumn 
inside a GCM grid cell. The parameterizations for cloud activation commonly assume that supersaturation is produced only by the adiabatic cooling of ascending parcels of air (Ghan et al., 2011), which is why the negative side of the vertical velocity PDF is left unused.

For this paper, a Gaussian PDF is implemented to provide a simple approximation of the vertical velocity PDF shape. The resolved GCM-scale vertical velocity $\langle w\rangle$ is taken as the mean of the PDF $(\bar{w})$. Lohmann et al. (2007) parameterized the effective vertical velocity for GCM grid cells as

$w^{\mathrm{eff}}=\langle w\rangle+1.33 \sqrt{\mathrm{TKE}}$.

We will use a similar TKE term (second term on the righthand side in Eq. (2)) to parameterize the standard deviation of the vertical velocity $\operatorname{PDF}\left(\sigma_{w}\right)$, so that

$\sigma_{w}=C \sqrt{\mathrm{TKE}}$,

where $C$ is a scaling coefficient. For a direct comparison with the standard model version using GCM-scale cloud microphysics, we match the average magnitude of $w_{j, k}$ from the new parameterization with the magnitude of $w^{\text {eff }}$ (Eq. 2). It can be easily shown (Fountoukis et al., 2007; Morales and Nenes, 2010) for a Gaussian distribution with mean at $0 \mathrm{~ms}^{-1}$ that the average vertical velocity over the positive side of the PDF is given by $w^{+} \approx 0.79 \sigma_{w}$. This can serve as a rough estimate in a global climate model, since $\langle w\rangle$ is usually very small. To ensure that $w^{\text {eff }} \approx w^{+}$, we set $C=1.33 / 0.79=1.68$. Interpreting $w^{\text {eff }}$ simply as the mean over the positive side of the PDF is not necessarily correct, but it serves the purpose for our comparison. However, one should also note that using $C=1.68$ for $\sigma_{w}$ can be viewed as unphysical, as it implies that small-scale variations in vertical velocity contain more energy than the TKE. Effects of this assumption will be presented and accounted for later in Sect. 5.3.

We assume that the coupling between vertical velocity and cloud thermodynamics is weak at cloud base of stratiform clouds, similar to Morales and Nenes (2010). Thus, there is no correlation between cloud-base vertical velocity and cloud structure.

\subsection{Supersaturation and cloud activation}

The parameterization for cloud activation (Abdul-Razzak et al., 1998; Abdul-Razzak and Ghan, 2000) has been modified to operate in the subcolumn space. In the parameterization, a balance equation for maximum supersaturation (Leaitch et al., 1986) in an ascending parcel of air is solved for individual subcolumns:

$\frac{\mathrm{d} S_{j, k}}{\mathrm{~d} t}=A(T) w_{j, k}-B(p, T) \frac{\mathrm{d} q_{l}^{*}}{\mathrm{~d} t}$.
Here $S_{j, k}$ denotes water vapour supersaturation in subcolumn $j$ at model level $k, A$ is a function of temperature $(T)$ and $B$ is a function of temperature and pressure ( $p$ ) (for a more detailed view on the solution method, see Abdul-Razzak et al., 1998). The first term on the right-hand side of Eq. (4) represents the production of supersaturation due to adiabatic cooling as the air parcel is ascending, while the second term represents a sink due to condensation on existing droplets. The condensation rate of water during the activation process is denoted by $\frac{\mathrm{d} q_{l}^{*}}{\mathrm{~d} t}$. The subcolumns do not include any perturbation in pressure or temperature from the GCM mean state. Thus, for a given thermodynamic state and aerosol size distribution in the GCM grid cell, the subcolumn distribution of $S^{\max }$ depends solely on the distribution of $w$, according to Eq. (4).

The subcolumn distribution of $S_{j, k}^{\max }$ yields the maximum number of newly activated droplets $N_{j, k}^{\text {act }}$ by finding the critical radius for aerosol particles, above which the particles can act as CCN (Ghan et al., 2011). For GCM-scale nucleation rate we use the same assumption as in the default ECHAM5.5-HAM2 (Lohmann et al., 1999):

$Q_{k}^{\text {nucl }}=\operatorname{MAX}\left(0, \frac{1}{\Delta t}\left(\left\langle N^{\text {act }}\right\rangle_{k}-\left\langle N^{\text {old }}\right\rangle_{k}\right)\right)$,

where, in this case, $N^{\text {old }}$ is the cloud droplet number concentration from the last time step. The brackets refer to the GCM-scale mean values. For $N^{\text {act }}$, the GCM-scale in-cloud value is taken as the ensemble mean over cloudy subcolumns simply as

$\left\langle N^{\mathrm{act}}\right\rangle_{k}=\frac{1}{c_{k} \mathcal{J}} \sum_{j=1}^{\mathcal{J}} N_{j, k}^{\mathrm{act}}$,

where $\mathcal{J}$ is the total number of subcolumns in each GCM grid column and $c_{k}$ is the fraction of cloudy subcolumns in the ensemble ( $N_{j, k}^{\text {act }}=0 \mathrm{~cm}^{-3}$ for cloud-free subcolumns). More specifically, in the subcolumn space, the CDNC profiles are constructed from surface upwards. The cloudy portion of a GCM grid cell can potentially contain both cloudbase and in-cloud subcolumn points. For subcolumns representing a cloud base at a given model level, $N_{j, k}^{\text {act }}$ is assigned as an initial CDNC. For in-cloud subcolumn levels, CDNC is determined by the number of nucleated droplets at their corresponding cloud-base levels according to the adiabatic assumption. However, as implied by Eq. (5), we do not allow nucleation to decrease the mean CDNC. Thus, the fraction

$f_{k}=\operatorname{MAX}\left(1, \frac{\left\langle N^{\text {old }}\right\rangle_{k}}{\left\langle N^{\text {act }}\right\rangle_{k}}\right)$

is used to adjust $N_{j, k}^{\text {act }}$ in the case of $f_{k}>1$, i.e. when $\left\langle N^{\text {act }}\right\rangle_{k}$ $<\left\langle N^{\text {old }}\right\rangle_{k}$. This ensures that the subcolumn ensemble mean CDNC is larger or equal to the mean CDNC from the last time step. We now get the expression for the final subgrid CDNC after nucleation as $N_{j, k}=f_{k} N_{j, k}^{\text {act }}$. 


\subsection{Radiative transfer}

Radiative transfer is computed using the McICA radiation scheme already implemented in our ECHAM5 configuration. The subcolumns are sampled randomly for radiation calculations, which then follow the standard approaches. The set-up of McICA follows the CLDS approach in Räisänen et al. (2007). Random sampling of subcolumns is confined to the cloudy part of the GCM column, while for clear-sky calculations the GCM columns are assumed horizontally uniform.

The cloud overlap is described by the generalized overlap method (Hogan and Illingworth, 2000; Räisänen et al., 2004), which is employed when the vertical cloud profiles are created in SCG. In generalized overlap, the degree of overlap changes gradually from maximum towards random overlap with increasing distance between layers. The relative contribution between these two basic overlap assumptions depends on decorrelation lengths defined for cloud fraction and cloud condensate (assumed $2 \mathrm{~km}$ and $1 \mathrm{~km}$, respectively).

\section{Experiments}

In this section we present configuration details for the model simulations used to evaluate the primary impacts of the new subgrid parameterizations. The model is run for a $5 \mathrm{yr}$ period (2001-2005) in all experiments with prescribed climatological sea surface temperatures. All the simulations are performed with T42L19 resolution and with a $30 \mathrm{~min}$ time step. The SCG framework is set up to use 50 subcolumns for the cloudy portion of the GCM grid column.

Next, each experiment is described more thoroughly. A summary of the experiments with their key parameters and configuration options is given in Table 1 .

\subsection{Experiment REF}

The experiment REF serves as the point of reference using the standard configuration of ECHAM5.5-HAM2 with the SCG and McICA radiation scheme active. The simulation includes cloud layers determined by the SCG with subgrid variations in cloud condensate, while CDNC is assumed uniform inside the GCM grid cell. The subgrid-scale variations in condensate amount are considered for radiative transfer but not for cloud microphysics. Vertical velocity for cloud activation is given by the effective vertical velocity according to Eq. (2) (Lohmann et al., 2007).

\subsection{Experiments SUBW and SUBWRT}

The most straightforward implementation of the subcolumn cloud microphysical parameterizations is presented in the experiments SUBW and SUBWRT. In these simulations, cloud activation and CDNC are calculated individually in each subcolumn with the newly implemented subgrid pa-
Table 1. List of experiments indicating the key configuration details. SGW refers to the subgrid treatment of vertical velocity and cloud activation, while the column labelled as $w$ shows details of the vertical velocity treatment. The terms "ccraut" and "cauloc" refer to model closure parameters for autoconversion rate and accretion, respectively. See text for further description.

\begin{tabular}{lllcc}
\hline Experiment & SGW & $w$ & ccraut & cauloc \\
\hline REF & No & Lohmann et al. (2007) & 7 & 3 \\
SUBW & Yes & $\sigma_{w}=1.68 \sqrt{\mathrm{TKE}}$ & 7 & 3 \\
SUBWRT & Yes & $\sigma_{w}=1.68 \sqrt{\mathrm{TKE}}$ & 4 & 2 \\
W_ADJ1 & Yes & $\sigma_{w}=\sqrt{2 \mathrm{TKE}}$ & 4 & 2 \\
W_ADJ2 & Yes & $\sigma_{w}=\sqrt{\frac{2}{3} \mathrm{TKE}}$ & 4 & 2 \\
\hline
\end{tabular}

rameterization for vertical velocity. The only difference between SUBW and SUBWRT lies in the values of closure ("tuning") parameters. SUBW uses identical parameters with REF, while SUBWRT is retuned to restore the global-mean radiative balance at the top of the atmosphere (TOA). Specifically, the linear scaling factors for the process rates of autoconversion of cloud droplets and accretion of cloud droplets by rain (ccraut and cauloc in the model code, respectively) are reduced.

\subsection{Experiments W_ADJ1 and W_ADJ2}

To investigate the effect of adjusting the width of the vertical velocity PDF, the experiments W_ADJ1 and W_ADJ2 are performed with $\sigma_{w}=\sqrt{2 \mathrm{TKE}}$ and $\sigma_{w}=\sqrt{\frac{2}{3} \mathrm{TKE}}$. Like so, W_ADJ1 assumes that all of the turbulent kinetic energy is associated with fluctuations in vertical motion of air, while W_ADJ2 assumes isotropic turbulence. Both of these experiments are otherwise identical to SUBWRT.

\section{Results}

The direct impacts on cloud properties due to the subcolumn treatment of cloud microphysics are presented first. Second, the consequent impacts on cloud radiative effects are presented, followed by a brief overview on general model climatology. For a fair comparison with REF, the width of the PDF for $w$ in the experiments SUBW and SUBWRT was deliberately set so that, on average, the vertical velocity for cloud activation matches the $w^{\text {eff }}$ used in REF. This is indeed the case, as shown in Fig. 2 depicting the lower-tropospheric vertical velocity for REF and SUBW: the simulated global-mean vertical velocity is almost identical in the two simulations and the local differences are most often below $0.1 \mathrm{~m} \mathrm{~s}^{-1}$. 

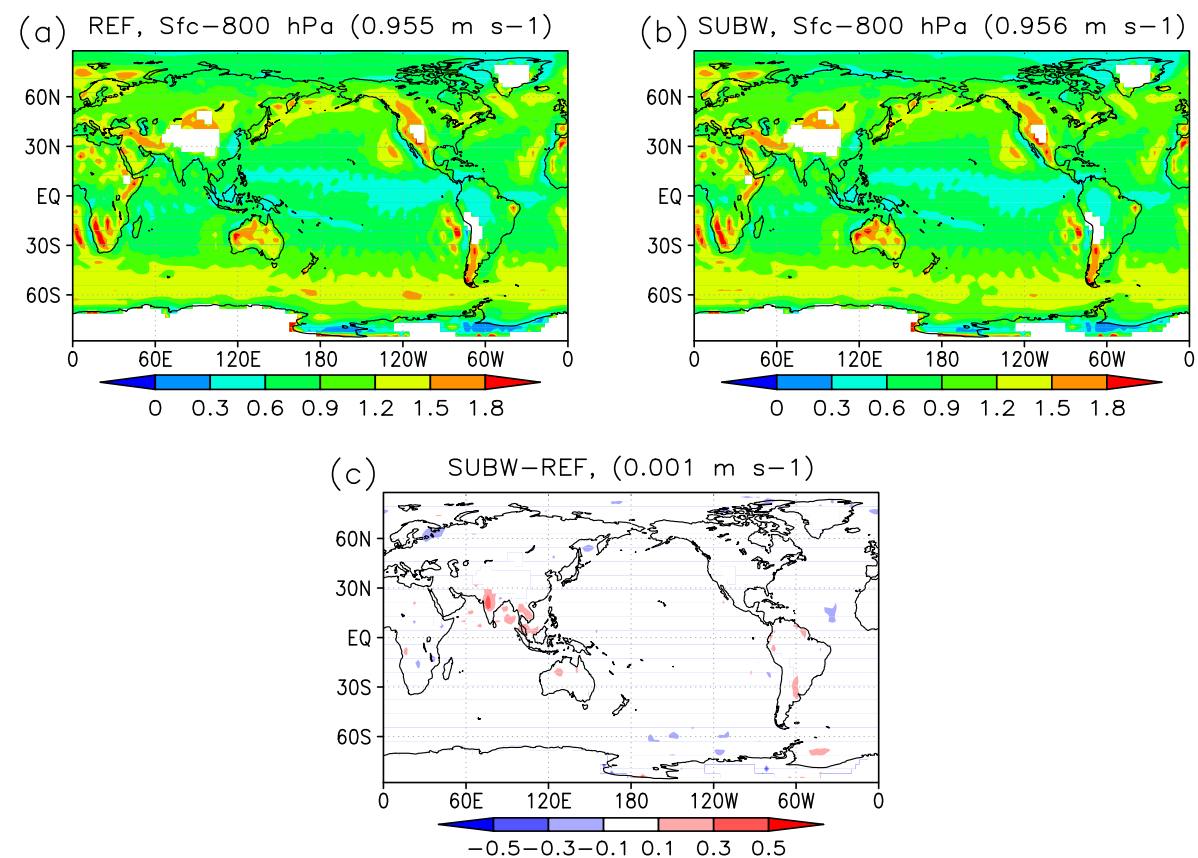

Fig. 2. Annual-mean vertical velocity $\left(\mathrm{m} \mathrm{s}^{-1}\right)$ for cloud activation averaged from surface to the $800 \mathrm{hPa}$ pressure level: (a) REF, (b) SUBW and (c) the difference of SUBW-REF. Global-mean values are indicated in parentheses.

Table 2. Global-mean cloud properties: LWP and IWP are for liquid and ice water paths $\left(\mathrm{g} \mathrm{m}^{-2}\right)$ and $C_{\text {tot }}$ is the total cloud fraction $[0,1]$. $\mathrm{CDNC}$ at cloud top is the all-sky mean value for warm clouds over all time steps $\left(\mathrm{cm}^{-3}\right)$.

\begin{tabular}{lcccc}
\hline Experiment & LWP & IWP & CDNC at cloud top & $C_{\text {tot }}$ \\
\hline REF & 50.71 & 7.05 & 21.48 & 0.720 \\
SUBW & 38.30 & 6.95 & 16.08 & 0.712 \\
SUBWRT & 50.87 & 7.08 & 18.57 & 0.722 \\
W_ADJ1 & 49.27 & 7.06 & 17.27 & 0.721 \\
W_ADJ2 & 44.78 & 7.06 & 12.99 & 0.717 \\
\hline
\end{tabular}

\subsection{Cloud properties}

Global-mean cloud parameters averaged over the $5 \mathrm{yr}$ period are summarized in Table 2: the liquid and ice water paths (LWP and IWP, respectively) as well as the all-sky global-mean CDNC at cloud top and the total cloud fraction are listed for REF, SUBW and SUBWRT (plus the remaining experiments W_ADJ1 and W_ADJ2, which are discussed later in Sect. 5.3). While the total cloud fraction and IWP show only minor changes, global-mean LWP and CDNC at cloud top are substantially smaller in SUBW than in REF. For closer inspection, we present vertically averaged in-cloud properties for the lower troposphere (from surface to $800 \mathrm{hPa}$ ), where we expect most of the changes to take place because only parameterizations for warm clouds have been modified.
Figure $3 \mathrm{a}$ and $\mathrm{b}$ illustrate the $5 \mathrm{yr}$ mean lower-tropospheric CDNC for the experiments REF and SUBW, respectively, and the difference between the two experiments is given in Fig. 3c. SUBW shows a strong decrease in CDNC over the continents compared to REF, while for marine areas a slight but widespread decrease is seen. However, parts of the remote Southern Hemisphere marine regions are almost unaffected, and CDNC is even slightly increased in the marine stratocumulus regions of the eastern Pacific and Atlantic oceans. Overall, the global-mean CDNC is approximately $26 \%$ smaller in SUBW than in REF. The strong decrease in CDNC is most likely due to modulation of the interplay between subgrid distribution of vertical velocity and the large-scale $\mathrm{CCN}$ environment. It can be argued that vertical velocity is more important than the number of $\mathrm{CCN}$ for CDNC in heavily polluted areas because of the competition for cloud water between droplets, while the opposite is true for more pristine regions (Reutter et al., 2009). In polluted areas, samples with small $w$ (i.e. smaller than $w^{\text {eff }}$ ) dominate the corresponding subcolumn ensemble of the number of activated droplets, because CDNC increases non-linearly with increasing $w$. Therefore, the average number of activated cloud droplets and, consequently, the GCM-scale mean CDNC is smaller in SUBW than in REF (as seen especially for continental regions in Fig. 3c), even though the average vertical velocity is similar. In contrast, in the pristine marine areas, most of the $\mathrm{CCN}$, comprising fewer particles, are activated already by rather low vertical velocity at cloud base. Thus, the low end of the spectrum for subcolumn vertical 

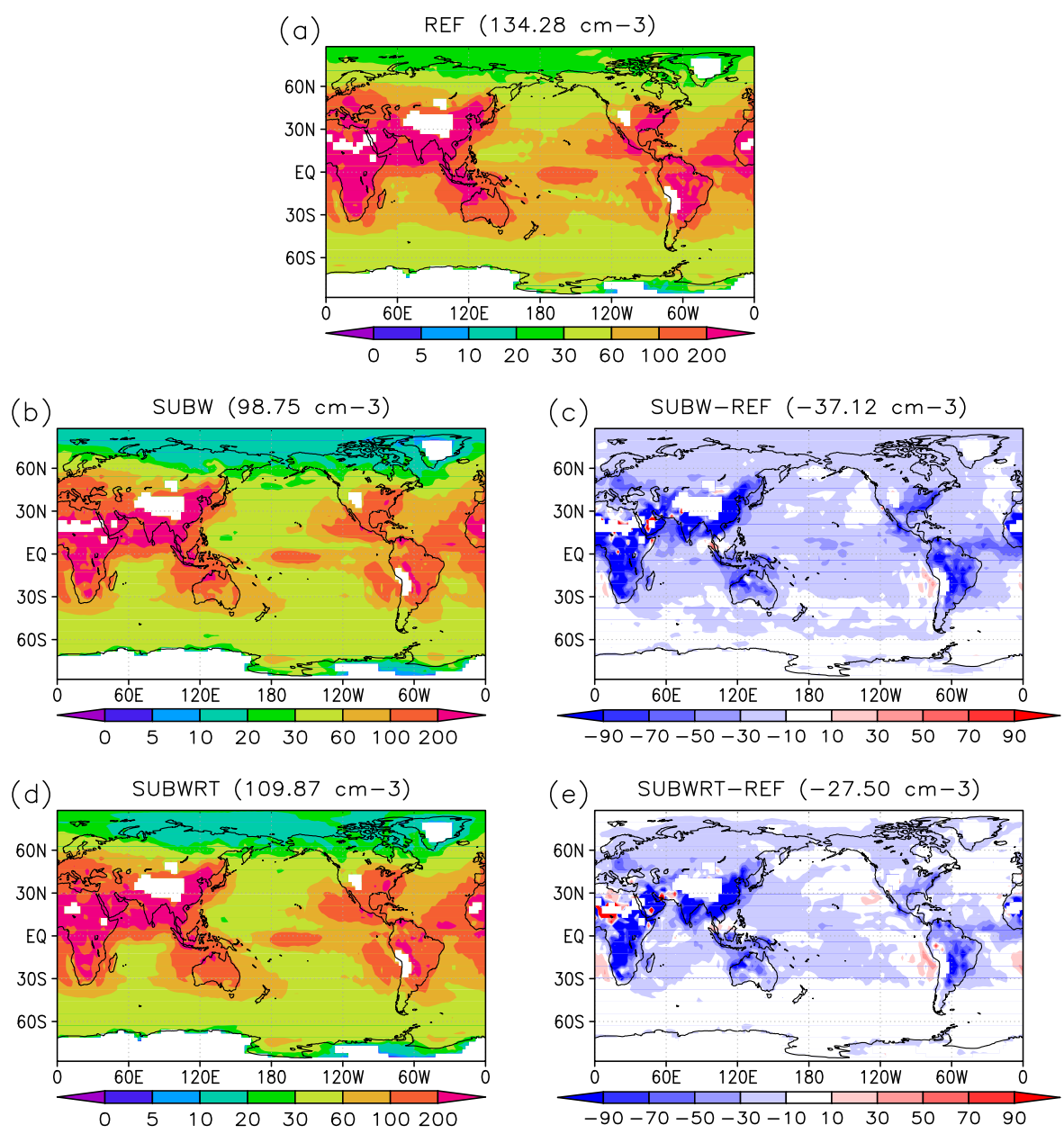

Fig. 3. Annual-mean in-cloud CDNC $\left(\mathrm{cm}^{-3}\right)$ averaged from surface to the $800 \mathrm{hPa}$ pressure level: (a) REF, (b) SUBW, (c) the difference of SUBW-REF, (d) SUBWRT, and (e) the difference of SUBWRT-REF.

velocity ensemble is not as dominant as it is for the more polluted environment, and the resulting mean CDNC is closer to that obtained using $w^{\text {eff }}$ (as seen e.g. for the southern marine areas in Fig. 3c for SUBW).

Similar results are also seen for the low-tropospheric liquid water content (LWC) shown in Figure 4a-c. As compared to REF, the LWC is globally decreased in SUBW, in accordance with the decrease in LWP shown in Table 2. The strongest decrease again takes place over the continents, with LWC locally up to $50 \%$ smaller in SUBW than in REF. The global-mean LWC is decreased by $22 \%$. The decrease in LWC can be explained by the autoconversion process that represents the formation of drizzle and rain by the largest cloud droplets. The autoconversion rate is parameterized as in Khairoutdinov and Kogan (2000), given in $\mathrm{kg} \mathrm{kg}^{-1} \mathrm{~s}^{-1}$ as

$Q_{j, k}^{\text {aut }} \propto \operatorname{LWC}_{j, k}^{2.47} N_{j, k}^{-1.79}$,

where $N$ (or CDNC) is given in $\mathrm{cm}^{-3}$ (the closure parameter for autoconversion rate ccraut is part of the proportionality factor in Eq. (8)). First, the reduction in the mean CNDC in
SUBW leads to an increase in $Q^{\text {aut }}$ because of the inverse proportionality to CDNC in Eq. (8). Second, because $Q^{\text {aut }}$ is strongly non-linear with respect to $\mathrm{CDNC}$, subgrid variation in CDNC acts by itself to increase the average $Q^{\text {aut }}$ (consider that e.g. a $50 \%$ reduction in CDNC from its mean value increases $Q^{\text {aut }}$ more than a $50 \%$ increase in CDNC reduces it). By the same token, subgrid variations in LWC also tend to increase the average $Q^{\text {aut }}$ because of the non-linear dependency on LWC $\left(\propto \mathrm{LWC}^{2.47}\right)$. The latter two effects likely explain the widespread decrease in LWC in the SUBW experiment, extending beyond the areas with the largest reduction in CNDC. The result regarding decreased LWC is qualitatively similar to the results obtained by Morales and Nenes (2010), who demonstrated that considering the subgrid vertical velocity distribution leads to stronger conversion of cloud water into rain by autoconversion process, as compared to using an effective mean vertical velocity. The decrease in LWC also leads to a slightly decreased low-level cloud fraction (defined here as the cloud volume fraction below $800 \mathrm{hPa}$ ) in SUBW, even though only a very small difference was seen 

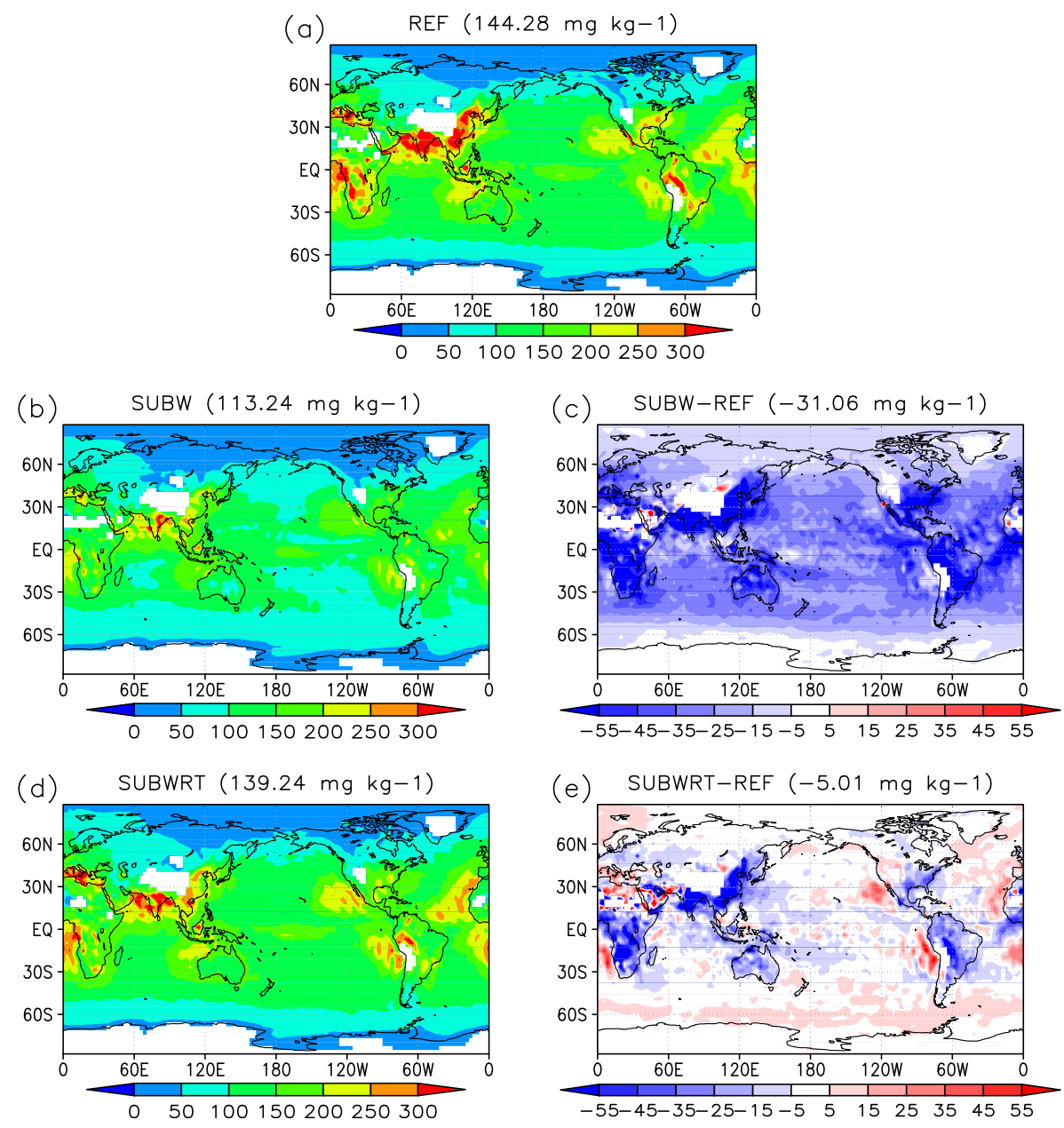

Fig. 4. Same as Fig. 3 but for in-cloud LWC $\left(\mathrm{mg} \mathrm{kg}^{-1}\right)$.

in the total global cloud cover. This is due to the tendencies in cloud water content affecting the statistics of total water, and hence cloud fraction, in the Tompkins (2002) cloud cover scheme. The global-mean low-level cloud fraction is 0.137 in SUBW as compared with 0.143 in REF. The largest local difference of -0.04 occurs over northern Russia, while over oceans there is a widespread difference of -0.01 .

Since the LWP over the oceans is unrealistically low in SUBW $\left(42.4 \mathrm{~g} \mathrm{~m}^{-2}\right.$ as compared with an observed range of $50-84 \mathrm{~g} \mathrm{~m}^{-2}$ used in Lohmann and Ferrachat, 2010), retuning the model is necessary in order to restore a more realistic representation of the cloud water content and, consequently, the global radiation budget (discussed in Sect. 5.2.1). Thus, the process rate coefficients for autoconversion and accretion (ccraut and cauloc, respectively) are reduced in order to decrease the removal of liquid water from the clouds (see Table 1).

In the retuned experiment SUBWRT, the global-mean LWP is similar to that in REF (approximately $51 \mathrm{~g} \mathrm{~m}^{-2}$; see Table 2) and the mean over oceans in SUBWRT is $56.7 \mathrm{~g} \mathrm{~m}^{-2}$, which is slightly larger than in $\operatorname{REF}\left(54.8 \mathrm{~g} \mathrm{~m}^{-2}\right)$.
Figure $4 \mathrm{~d}$ and e show the impact of retuning on the lowertropospheric LWC. LWC is clearly higher in SUBWRT than in SUBW, especially in the marine stratocumulus areas and over mid-latitude oceans. In these regions LWC in SUBWRT even locally exceeds that in REF. However, over several continental regions, LWC is still substantially smaller than in REF. The impact of retuning on CDNC is presented in Fig. 3d and e, where an increase in SUBWRT with respect to SUBW is seen as well. However, the relative effect is smaller than that for LWC as the global-mean CDNC in SUBWRT is still about $18 \%$ smaller than in REF and large negative regional anomalies still appear over the continents. The areas with decreased LWC in SUBWRT compared to REF (Fig. 4e) coincide with the largest negative anomalies in CDNC (Fig. 3e), again reflecting the connection between CDNC and LWC through drizzle formation by autoconversion. Similarly, the areas in SUBWRT with CDNC quite similar to REF now have slightly higher LWC. Changes in lower-tropospheric cloud fraction follow the changes in LWC, but the differences between SUBWRT and REF are still quite small. 
Table 3. Net radiative balance at the top of the atmosphere (TOA) plus cloud radiative effect parameters at the TOA and the surface (Sfc). Absolute values are given for the experiment REF, while for the other experiments the difference with respect to REF or SUBWRT is shown, as indicated in the first column. All values are given in $\mathrm{W} \mathrm{m}^{-2}$.

\begin{tabular}{lrrrrr}
\hline Experiments & Net TOA & LW CRE TOA & SW CRE TOA & LW CRE Sfc & SW CRE Sfc \\
\hline REF & -0.09 & 27.29 & -54.47 & 29.58 & -59.11 \\
SUBW-REF & 3.64 & -0.55 & 4.08 & -1.02 & 4.80 \\
SUBWRT-REF & -0.50 & -0.12 & -0.41 & 0.13 & -0.50 \\
W_ADJ1-SUBWRT & 0.49 & -0.03 & 0.69 & -0.08 & 0.81 \\
W_ADJ2-SUBWRT & 2.69 & -0.17 & 2.88 & -0.65 & 3.36 \\
\hline
\end{tabular}

\subsection{Radiative balance}

\subsubsection{Impact of the subgrid parameterizations}

Table 3 summarizes the radiative fluxes for the model experiments. Global-mean values for the net total radiative budget at TOA, and the LW and SW cloud radiative effects (CREs) are listed for REF, while for SUBW and SUBWRT the difference with respect to REF is presented. Introducing the subcolumn vertical velocity and CDNC sets the total radiative budget off balance by $3.6 \mathrm{~W} \mathrm{~m}^{-2}$, for the most part due to reduction in CDNC and the induced stronger removal of liquid water from clouds due to enhanced autoconversion. Overall, the total radiative budget balances at quite low levels of outgoing longwave radiation (OLR) and net shortwave flux at TOA (approximately $231 \mathrm{~W} \mathrm{~m}^{-2}$ for REF), regardless of the model configuration. This was also found for ECHAM5.3 (Räisänen and Järvinen, 2010) and was ascribed to low clearsky OLR and too strong SW CREs. In addition, in the current paper, a persistent feature of quite high total cloud fraction of over $70 \%$ is seen (Table 2), which contributes to the CRE and the global radiation budget in general.

Considering the CRE at TOA, the largest differences are seen for SW radiation. Figure 5a and b show the difference in SW CRE for SUBW and SUBWRT with respect to REF. While SW CRE in SUBW is weaker (i.e. less negative) than in REF almost globally in response to the smaller CDNC and LWC, SUBWRT shows weaker SW CRE mainly over the continental regions of south-eastern Asia and the eastern parts of North and South America. These coincide with the optically thinner clouds due to reduction in CDNC and LWC, as well as with a small decrease in low-level cloud fraction (by up to 0.01). In contrast, a preference for stronger SW CRE is seen over the mid-latitude oceans and eastern Pacific stratocumulus regions off the coasts of North and South America, as well as in the Atlantic off the coast of Namibia in SUBWRT. For the marine stratocumulus these differences are explained mainly by the cloud microphysical properties, i.e. increased LWC and slightly higher CDNC illustrated in Section 5.1. In addition, a small increase (by less than 0.01) in cloud fraction also contributes to the stronger SW CRE. For mid-latitude oceans, the stronger SW CRE is caused by a slight increase in LWC as well as in low-level cloud fraction (generally by $0.01-0.02$ ), whereas $\mathrm{CDNC}$ is rather similar to REF.

The direct impact in SUBW is thus to weaken the global SW CRE by $4.08 \mathrm{Wm}^{-2}$ from the $-54.47 \mathrm{Wm}^{-2}$ seen in REF (Table 3). In SUBWRT, this is compensated by retuning, after which the difference to REF is $-0.41 \mathrm{~W} \mathrm{~m}^{-2}$. The clouds in SUBWRT are therefore on average slightly more reflective than in REF. Although the continental areas with high aerosol load feature considerably less reflective clouds in SUBWRT than in REF, this is more than compensated by oceanic clouds, which generally feature slightly stronger SW CRE in SUBWRT.

Differences in LW CRE at TOA between SUBW/SUBWRT and REF are shown in Figure 5c and d. In both cases, differences are seen mostly in tropical latitudes. The global-mean stays close to the recently published estimate of $26.7 \mathrm{Wm}^{-2}$ (Stephens et al., 2012, Fig. B1) in all our experiments. As shown in Table 3, the strongest LW CRE at the TOA occurs in REF $\left(27.29 \mathrm{~W} \mathrm{~m}^{-2}\right)$, while the weakest value is seen for SUBW $\left(26.74 \mathrm{Wm}^{-2}\right.$, in correlation with the lowest LWP). Especially for SUBWRT, the differences with respect to REF are rather small. This is not particularly surprising because the LW fluxes at TOA are mainly affected by high-altitude clouds such as cirrus. The newly implemented parameterizations mainly affect warm low-level clouds whose temperature is relatively close to surface temperatures, so their effect on LW CRE is limited.

Finally, an additional model run was performed to quantify the difference in radiative fluxes between horizontally homogeneous and horizontally varying cloud properties. In other words, what is the impact on radiative fluxes if the subcolumn values of LWC and CDNC are overridden with their subcolumn ensemble means in each GCM grid cell for use in radiative transfer calculations? While little difference was seen in LW CRE as compared to SUBW in terms of the global-mean (increased by $0.21 \mathrm{~W} \mathrm{~m}^{-2}$ ), SW CRE was $-1.7 \mathrm{~W} \mathrm{~m}^{-2}$ stronger in this experiment than in SUBW. This is in close agreement with earlier results by Räisänen and Järvinen (2010), who found a $2 \mathrm{~W} \mathrm{~m}^{-2}$ reduction in globalmean SW CRE due to including subgrid cloud structure in offline radiation calculations based on ECHAM5.3 data. 

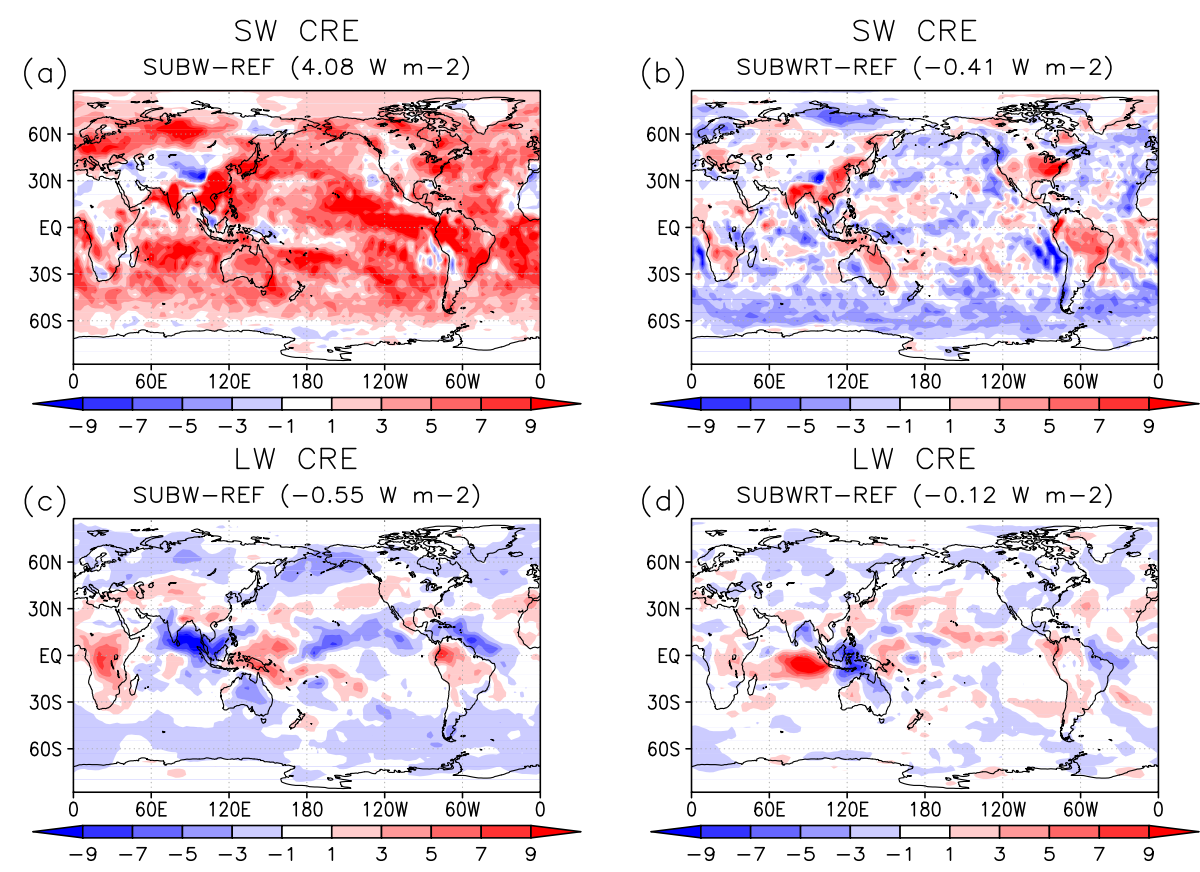

Fig. 5. Difference in annual-mean TOA shortwave cloud radiative effects $\left(\mathrm{W} \mathrm{m}^{-2}\right)$ between (a) SUBW and REF, and (b) SUBWRT and REF. Differences for longwave CRE are given similarly in (c) and (d).

\subsubsection{Comparison with satellite observations}

The simulated cloud radiative effects are compared with space-borne measurements from the CERES EBAF satellite dataset (Loeb et al., 2009). Compared to CERES EBAF data, the simulated clouds generally reflect too much solar radiation in all of our experiments, and the LW CRE is marginally higher than in the CERES data. The differences in LW and SW CRE between model simulations and CERES EBAF are shown in Figure 6. The global-mean SW CRE in REF is $7.21 \mathrm{~W} \mathrm{~m}^{-2}$ stronger than the CERES estimate of $-47.26 \mathrm{~W} \mathrm{~m}^{-2}$. The measured level of SW CRE is not reached even by SUBW where the SW CRE is $-50.39 \mathrm{~W} \mathrm{~m}^{-2}$ (see Table 3).

The LW CRE in our simulations exceeds the CERES estimate of $26.18 \mathrm{~W} \mathrm{~m}^{-2}$ by $0.5-1 \mathrm{Wm}^{-2}$. Overall, the differences between the model experiments REF, SUBW and SUBWRT are smaller than their respective differences from the CERES EBAF dataset.

\subsection{Sensitivity to vertical velocity distribution width}

We consider the effect of adjusting $\sigma_{w}$, i.e. the magnitude of vertical velocity fluctuations, by comparing the experiments W_ADJ1 and W_ADJ2 with SUBWRT. Table 2 shows that smaller $\sigma_{w}$ decreases the global-mean cloud top CDNC as well as the LWP, with the latter explained by similar arguments as in Sect. 5.1. The same is true for the lower-tropospheric CDNC in the two experiments, which, along with the difference with respect to SUBWRT, is pre- sented in Figure 7a-d. The lower-tropospheric CDNC in W_ADJ1 is on average $9.76 \mathrm{~cm}^{-3}$ smaller than in SUBWRT. The corresponding difference for W_ADJ2 is $-27.69 \mathrm{~cm}^{-3}$. Figure $7 \mathrm{e}-\mathrm{h}$ show the results for lower-tropospheric LWC, which is, subsequently, only slightly decreased in W_ADJ1 with respect to SUBWRT (by $3.39 \mathrm{mg} \mathrm{kg}^{-1}$ ). Again, in W_ADJ2, the decrease is larger (by $15.31 \mathrm{mg} \mathrm{kg}^{-1}$ ).

Figure 8 shows the impact of adjusted $\sigma_{w}$ on longwave and shortwave CRE. The global-mean impacts on LW CRE are minor. The SW CRE for W_ADJ1 and W_ADJ2 are weaker (less negative) than that for SUBWRT, by $0.69 \mathrm{~W} \mathrm{~m}^{-2}$ and $2.88 \mathrm{~W} \mathrm{~m}^{-2}$, respectively. While only local anomalies are seen over the tropical oceans in both W_ADJ1 and W_ADJ2 for LW CRE, SW CRE shows more widespread differences with largest positive anomalies in the marine stratocumulus regions off the western coasts of South America and Africa. Overall, the impacts on cloud radiative properties due to adjusting the vertical velocity magnitude are more concentrated over the oceans, compared to the effects of implementing the subgrid parameterizations.

\subsection{Model climatology}

In addition to quantities directly related to clouds and radiation, basic climatological quantities, like temperature, surface pressure and precipitation, were analysed. For precipitation, a slight overall shift from convective to stratiform precipitation was noted in experiments with subgrid treatment of vertical velocity. The global-mean stratiform precipitation rate was $1.046 \mathrm{~mm} \mathrm{day}^{-1}$ in REF, $1.067 \mathrm{~mm} \mathrm{day}^{-1}$ in SUBW 

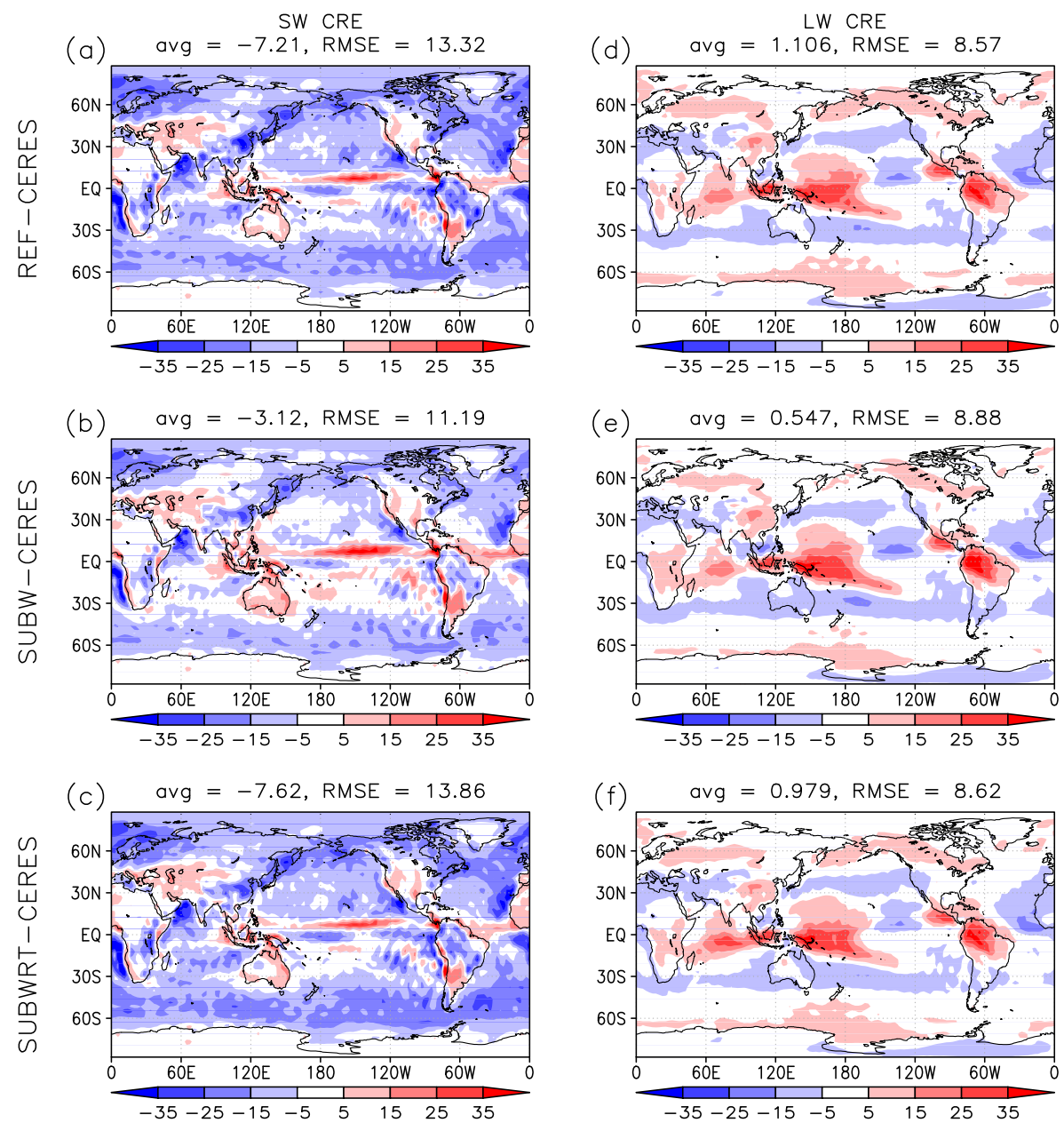

Fig. 6. Comparison of the shortwave and longwave cloud radiative effects at the TOA with CERES EBAF data. (a-c) show the difference in the SW CRE for REF, SUBW and SUBWRT, respectively. Panels (d-e) show a similar comparison for the LW CRE. The global-mean difference (avg) and root-mean-square error (RMSE) are shown on top of each panel in $\mathrm{W} \mathrm{m}^{-2}$.

and $1.055 \mathrm{~mm}_{\text {day }}{ }^{-1}$ in SUBWRT. The most consistent feature was a widespread but very slight increase of stratiform precipitation in the tropics in SUBW. For the SUBW experiment, the increased stratiform precipitation was partly compensated by reduced convective precipitation (globalmean values $1.844 \mathrm{~mm} \mathrm{day}^{-1}$ for SUBW as compared with $1.851 \mathrm{~mm} \mathrm{day}^{-1}$ for both REF and SUBWRT).

The differences in temperature and sea level pressure between the different simulations were quite minor and mostly statistically insignificant according to a two-tailed $t$ test. This is expected because the sea surface temperatures are prescribed to climatological values, which limits the impact due to cloud radiative effects. Furthermore, internal climate variability is substantial for the relatively short $5 \mathrm{yr}$ averages considered in this work, which reduces the signal-to-noise ratio.

\section{Discussion}

Explicit description of subgrid variability of vertical velocity and CDNC introduces notable differences compared to the existing implementation of McICA radiation and the stochastic cloud generator in ECHAM5.5-HAM2. The subcolumn approach allows the model to account for non-linearities related to subgrid variability in cloud microphysics not only in individual processes, such as cloud activation, but also in the interactions between different processes. Considering the microphysical properties of clouds explicitly in several subcolumns inside each GCM grid cell also increases the computational cost of the model: it takes about $20-25 \%$ longer to run the new model version (as in SUBW) compared to the standard implementation of McICA and the stochastic cloud generator (as in REF).

Gaussian PDF has been used extensively to simulate the small-scale variations in vertical velocity (e.g. Ghan et al., 1997) and was also employed in this study. However, we 

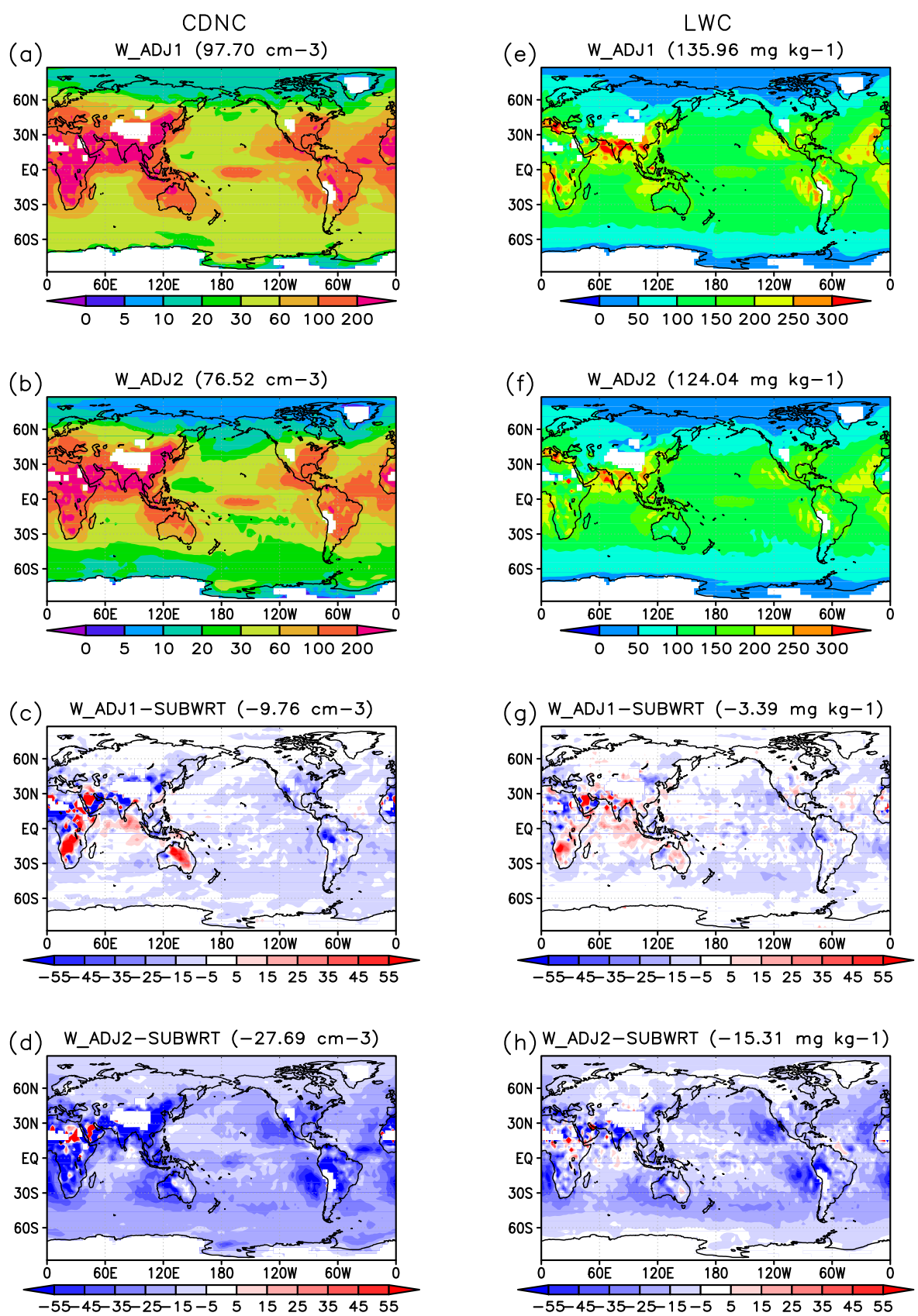

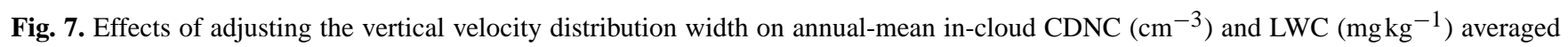
from surface to the $800 \mathrm{hPa}$ pressure level. (a) and (b): CDNC for the experiments W_ADJ1 and W_ADJ2. (c) and (d): the difference with respect to SUBWRT for W_ADJ1 and W_ADJ2. (e-h) are the same as (a-d) but for LWC.

speculate that more careful consideration of the characteristics of the PDF might be important for boundary layer clouds. Perhaps the most obvious such characteristic is the skewness: non-symmetrical vertical velocity PDF shapes in the boundary layer have been observed in measurements and model simulations (Moeng et al., 1990; Guo et al., 2008, 2010; Ghate et al., 2010; Lenschow et al., 2012). Our implementation of the subcolumn vertical velocity parameterization al- lows the PDF to be easily adjusted through the use of look-up tables. Although left outside the scope of the current paper, experiments with skewed vertical velocity distributions are part of our future plans.

Since the effects of the subcolumn cloud activation and autoconversion on CDNC and LWC were found to vary quite strongly across different regions with different aerosol characteristics, it is possible that these effects will induce 
SW CRE

(a) W_ADJ1-SUBWRT $(0.69 \mathrm{~W} \mathrm{~m}-2)$

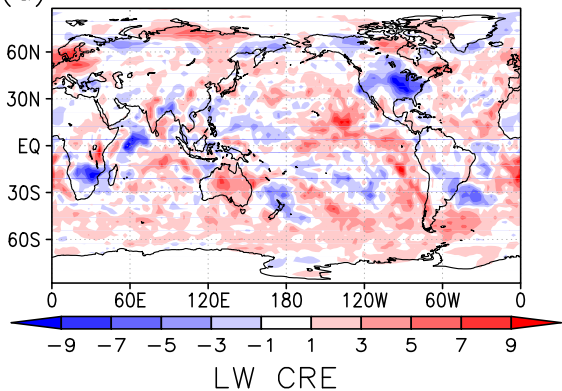

(c) W_ADJ1-SUBWRT $(-0.03 \mathrm{~W} \mathrm{m-2)}$

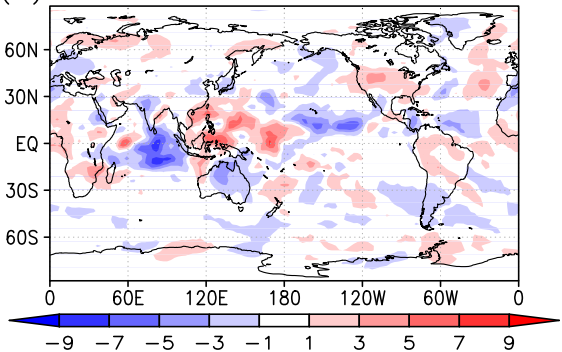

SW CRE

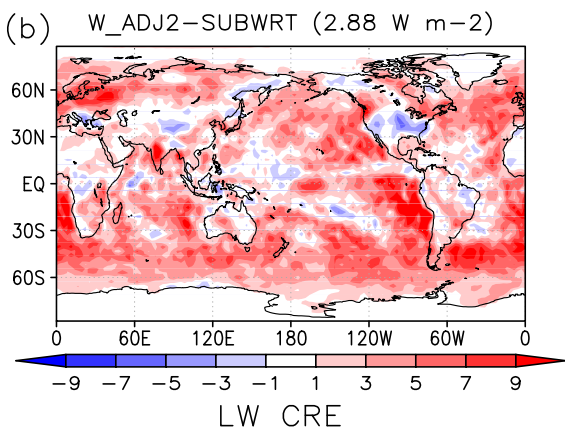

(d) W_ADJ2-SUBWRT $(-0.17 \mathrm{~W} \mathrm{m-2)}$

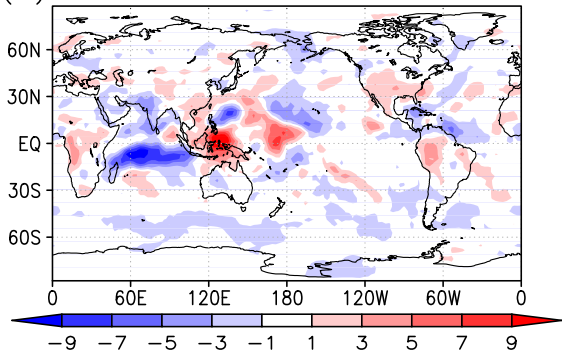

Fig. 8. Difference in annual-mean TOA shortwave cloud radiative effects $\left(\mathrm{W} \mathrm{m}^{-2}\right)$ between (a) W_ADJ1 and SUBWRT, and (b) W_ADJ2 and SUBWRT. Differences in longwave CRE are given similarly in panels (c) and (d).

perturbations in the model estimates of the indirect aerosol effects on radiation. Subgrid variability in clouds and retuning the closure parameters for autoconversion have been found to induce changes in the simulated aerosol indirect effects in earlier studies (Rotstayn, 2000; Golaz et al., 2011; Wang et al., 2012). The evaluation of the new model version should therefore be extended by exposing the model to preindustrial aerosol emission inventories and, perhaps, to future emission scenarios. Moreover, the McICA radiation scheme, as well as the standard radiation scheme in ECHAM5.5, includes an assumed minimum CDNC of $40 \mathrm{~cm}^{-3}$, which is applied to all cloudy subcolumns in our model. It has been shown that this assumption may induce artefacts to the model representation of the indirect aerosol effects (Hoose et al., 2009). We too recognize this as a possible caveat especially regarding the subcolumns, as it might artificially smooth out a part of the subgrid variability in the cloud radiative effects. The fraction of cloudy subcolumns for which the lowertropospheric CDNC is overridden by the minimum CDNC in our experiments was highest in the mid-latitudes, being typically $10-15 \%$ and locally up to $20 \%$ in the Southern Hemisphere.

\section{Summary}

This paper reported the implementation of a subgrid vertical velocity parameterization and subgrid versions of cloud microphysical parameterizations describing processes such as cloud droplet activation and autoconversion of cloud droplets to rain. Vertical velocity and cloud properties were calculated using stochastically generated cloudy subgrid columns, which can be directly applied by the McICA radiation scheme included in the model. This enabled the model to account for the inherent non-linearities in the entire process chain, from defining non-uniform cloud properties to calculating radiative fluxes at subgrid scale.

The brief model evaluation using the new subcolumn parameterizations revealed interesting effects on the interactions between different cloud processes. With the subcolumn vertical velocity parameterization and thus subgrid cloud activation switched on, CDNC was decreased especially over continental areas with high aerosol particle concentration. The decreased CDNC together with the non-linearity related to its subgrid variability induced stronger autoconversion of cloud water to rain, which resulted in decreased global mean LWP. Retuning the model closure parameters increased LWP back to the observed range, but a decrease in CDNC was seen even after retuning. This had an impact on the cloud radiative effects as well. While the impact on the longwave cloud radiative effect was quite weak, somewhat more pronounced differences were seen in the shortwave radiative effect. Continental areas with large reduction in CNDC and LWC were mostly associated with positive anomalies for shortwave cloud radiative effects, while the opposite was seen e.g. over mid-latitude oceans. Moreover, low-level cloud fraction seemed to follow the changes in LWC, although the differences were usually quite small. Nevertheless, the changes in cloud fraction affected radiation 
generally to the same direction as the changes in the in-cloud microphysical properties.

With the globally and regionally varying effects on CNDC and LWC, the new model version shows the importance of considering the small-scale variability of the two-moment cloud microphysical properties together with radiative transfer more explicitly than what has most often been done in the context of traditional parameterizations for global models.

Acknowledgements. This work has been supported by the Academy of Finland (project number 127210) and the European Commission's 7th Framework project COMBINE (contract number 226520). We also thank the two anonymous reviewers for their constructive comments on the manuscript.

Edited by: C. Hoose

\section{References}

Abdul-Razzak, H. and Ghan, S. J.: A parameterization of aerosol activation.2. Multiple aerosol types, J. Geophys. Res., 105, 68376844, 2000.

Abdul-Razzak, H., Ghan, S. J., and Rivera-Carpio, C.: A parameterization of aerosol activation. 1. Single aerosol type, J. Geophys. Res., 103, 6123-6131, 1998.

Cagnazzo, C., Manzini, E., Giorgetta, M. A., Forster, P. M. De F., and Morcrette, J. J.: Impact of an improved shortwave radiation scheme in the MAECHAM5 General Circulation Model, Atmos. Chem. Phys., 7, 2503-2515, doi:10.5194/acp-7-2503-2007, 2007.

Fountoukis, C., Nenes, A., Meskhidze, N., Bahreini, R., Conant, W. C., Jonsson, H., Murphy, S., Sorooshian, A., Varutbangkul, V., Brechtel, F., Flagan, R. C., and Seinfeld, J. H.: Aerosol-cloud drop concentration closure for clouds sampled during the International Consortium for Atmospheric Research on Transport and Transformation 2004 campaign, J. Geophys. Res., 112, D10S30, doi:10.1029/2006JD007272, 2007.

Fouquart, Y. and Bonnel, B.: Computations of solar heating of the Earth"s atmosphere: a new parameterization, Beitr. Phys. Atmos. 53, 35-62, 1980.

Fountoukis, C. and Nenes, A.: Continued development of a cloud droplet formation parameterization for global climate models, J. Geophys. Res., 110, D11212, doi:10.1029/2004JD005591, 2005.

Ghan, S. J., Leung, L. R., and Easter, R. C.: Prediction of cloud droplet number in a general circulation model, J. Geophys. Res., 102, 21777-21794, 1997.

Ghan, S. J., Abdul-Razzak, H., Nenes, A., Ming, Y., Liu, X., Ovchinnikov, M., Shipway, B., Meskhidze, N., Xu, J., and Shi, $\mathrm{X}$.: Droplet nucleation: physically-based parameterizations and comparative evaluation, J. Adv. Model. Earth Syst., 3, M10001, doi:10.1029/2011MS000074, 2011.

Ghate, V. P., Albrecht, B. A., and Kollias, P.: Vertical velocity structure of nonprecipitating continental boundary layer stratocumulus clouds, J. Geophys. Res., 115, D13204, doi:10.1029/2009JD013091, 2010.

Golaz, J.-C., Salzmann, M., Donner, L. J., Horowitz, L., W., Ming, Y., and Zhao, M.: Sensitivity of the aerosol indirect effect to sub- grid variability in the cloud parameterization of the GFDL atmosphere general circulation model AM3, J. Climate, 24, 31453160, doi:10.1175/2010JCLI3945.1, 2011.

Guo, H., Liu, Y., Daum, P. H., Senum, G. I., and Tao, W.-K.: Characteristics of vertical velocity in marine stratocumulus: comparison of large eddy simulations with observations, Environ. Res. Lett., 3, 045020, doi:10.1088/1748-9326/3/4/045020, 2008.

Guo, H., Golaz, J.-C., Donner, L. J., Larson, V. E., Schanen, D. P., and Griffin, B. M.: Multi-variate probability density functions with dynamics for cloud droplet activation in large-scale models: single column tests, Geosci. Model Dev., 3, 475-486, doi:10.5194/gmd-3-475-2010, 2010.

Hogan, R. J. and Illingworth, A., J.: Deriving cloud overlap statistics from radar, Q. J. Roy. Meteorol. Soc., 128, 2903-2909, 2000.

Hoose, C., Kristjansson, J. E., Iversen, T., Kirkevåg, A., Seland, Ø, and Gettelman, A.: Constraining cloud droplet number concentration in GCMs suppresses the aerosol indirect effect, Geophys. Res. Lett., 36, L12807, doi:10.1029/2009GL038568, 2009.

Hoose, C., Kristjansson, J. E., Arabas, S., Boers, R., Pawlowska, H., Puygrenier, V., Siebert, H., and Thouron, O.: Parameterization of in-cloud vertical velocities for cloud droplet activation in coarse-grid models: analysis of observations and cloud resolving model results. Proceedings of the 13th AMS Conference on Atmospheric Radiation, Portland, OR, USA, 28 June-2 July 2010.

Khairoutdinov, M. and Kogan, Y.: A new cloud physics parameterization in a Large-Eddy Simulation model of marine stratocumulus, Mon. Weather Rev., 128, 229-243, 2000.

Khvorostyanov, V. I. and Curry, J.: Parameterization of cloud drop activation based on analytical asymptotic solutions to the supersaturation equation, J. Atmos. Sci., 66, 1905-1925, 2009.

Leaitch, W. R., Strapp, J. W., and Isaac, G. A.: Cloud droplet nucleation and cloud scavenging of aerosol sulphate in polluted atmospheres, Tellus B, 38, 328-344, 1986.

Lenschow, D. H., Lothon, M., Mayor, S. D., Sullivan, P. P., and Canut, G.: A comparison of higher-order vertical velocity moments in the convective boundary layer from lidar with in situ measurements and large-eddy simulation, Bound.-Lay. Meteorol., 143, 107-123, doi:10.1007/s10546-011-9615-3, 2012.

Loeb, N. G., Wielicki, B. A., Doelling, D. R., Smith, G. L., Keyes, D. F., Kato, S., Manalo-Smith, N., and Wong, T.: Toward optimal closure of the Earth's top-of-atmosphere radiation budget, J. Climate, 22, 748-766, doi:10.1175/2008JCLI2637.1, 2009.

Lohmann, U. and Feichter, J.: Global indirect aerosol effects: a review, Atmos. Chem. Phys., 5, 715-737, doi:10.5194/acp-5-7152005, 2005.

Lohmann, U. and Ferrachat, S.: Impact of parametric uncertainties on the present-day climate and on the anthropogenic aerosol effect, Atmos. Chem. Phys., 10, 11373-11383, doi:10.5194/acp10-11373-2010, 2010.

Lohmann, U. and Roeckner, E.: Desing and performance of a new cloud microphysics scheme developed for the ECHAM general circulation model, Clim. Dynam., 12, 557-572, 1996.

Lohmann, U., Feichter, J., Chuang, C. C., and Penner, J. E.: Prediction of the number of cloud droplets in the ECHAM GCM, J. Geophys. Res., 104, 9169-9198, 1999.

Lohmann, U., Stier, P., Hoose, C., Ferrachat, S., Kloster, S., Roeckner, E., and Zhang, J.: Cloud microphysics and aerosol indirect effects in the global climate model ECHAM5-HAM, Atmos. Chem. Phys., 7, 3425-3446, doi:10.5194/acp-7-3425-2007, 
2007.

Ming, Y., Ramaswamy, V., Donner, L. J., and Phillips, V. T. J.: A new parameterization of cloud droplet activation applicable to general circulation models, J. Atmos. Sci., 63, 1348-1356, 2006.

Mlawer, E. J., Taubman, S. J., Brown, P. D., Iacono, M. J., and Clough, S. A.: Radiative transfer for inhomogeneous atmospheres: RRTM, a validated correlated-k model for the longwave, J. Geophys. Res., 102, 16663-16682, 1997.

Moeng, C.-H. and Rotunno, R.: Vertical-velocity skewness in the buoyancy-driven boundary layer, J. Atmos. Sci., 47, 1149-1161, 1990.

Morales, R. and Nenes, A.: Characteristic updrafts for computing distribution averaged cloud droplet number and stratocumulus cloud properties, J. Geophys. Res., 115, D18220, doi:10.1029/2009JD013233, 2010.

O'Donnell, D., Tsigaridis, K., and Feichter, J.: Estimating the direct and indirect effects of secondary organic aerosols using ECHAM5-HAM, Atmos. Chem. Phys., 11, 8635-8659, doi:10.5194/acp-11-8635-2011, 2011.

Pincus, R., Barker, H. W., and Morcrette, J.-J.: A fast, flexible, approximate technique for computing radiative transfer in inhomogeneous cloud fields, J. Geophys. Res., 108, doi:10.1029/2002JD003322, 2003.

Räisänen, P. and Järvinen, H.: Impact of cloud and radiation scheme modifications on climate simulated by the ECHAM5 atmospheric GCM, Q. J. Roy. Meteorol. Soc., 136, 1733-1752, doi:10.1002/qj.674, 2010.

Räisänen, P., Barker, H. W., Khairoutdinov, M. F., Li, J., and Randall, D. A.: Stochastic generation of subgrid-scale cloudy columns for large-scale models, Q. J. Roy. Meteorol. Soc., 130, 2047-2067, 2004.

Räisänen, P., Järvenoja, S., Järvinen, H., Giorgetta, M., Roeckner, E., Jylhä, K., and Ruosteenoja, K.: Tests of Monte Carlo Independent Column Approximation in the ECHAM5 atmospheric GCM, J. Climate, 20, 4995-5011, 2007.

Räisänen, P., Järvenoja, S., and Järvinen, H.: Noise due to Monte Carlo independent-column approximation: short-term and longterm impacts in ECHAM5, Q. J. Roy. Meteorol. Soc., 134, 481495, doi:10.1002/qj.231, 2008.

Reutter, P., Su, H., Trentmann, J., Simmel, M., Rose, D., Gunthe, S. S., Wernli, H., Andreae, M. O., and Pöschl, U.: Aerosoland updraft-limited regimes of cloud droplet formation: influence of particle number, size and hygroscopicity on the activation of cloud condensation nuclei (CCN), Atmos. Chem. Phys., 9, 70677080, doi:10.5194/acp-9-7067-2009, 2009.
Roeckner, E., Bäuml, G., Bonaventura, L., Brokopf, R., Esch, M., Giorgetta, M., Hagemann, S., Kirchner, I., Koernblueh, L., Manzini, E., Rhodin A., Schlese, U., Schulzweida, U., and Tompkins, A.: The atmospheric general circulation model ECHAM5, Part I: model description. Rep. 349, Max Planck Institute for Meteorology, Hamburg, Germany, 127 pp., 2003.

Roeckner, E., Brokopf, R., Esch, M., Giorgetta, M., Hagemann, S., Koernblueh, L, Manzini, E., Schlese, U., and Schulzweida, U.: Sensitivity of simulated climate to horizontal and vertical resolution in the ECHAM5 atmosphere model, J. Climate, 19, 37713791, 2006.

Rotstayn, L. D.: On the "tuning" of autoconversion parameterizations in climate models, J. Geophys. Res., 105, 15495-15507, doi:10.1029/2000JD900129, 2000.

Stephens, G. L., Li, J., Wild, M., Clayson, C. A., Loeb, N., Kato, S., L'Ecuyer, T., Stackhouse Jr, P. W., Lebsock, M., and Andrews, T.: An update on earth's energy balance in light of the latest global observations, Nat. Geosci., 5, 691-696, doi:10.1038/NGEO1580, 2012.

Tompkins, A. M.: A prognostic parameterization for the subgridscale variability of water vapor and clouds in large-scale models and its use to diagnose cloud cover, J. Atmos. Sci., 59, 19171942, 2002.

Vignati, E., Wilson, J., and Stier, P.: M7: an efficient sizeresolved aerosol microphysics module for large-scale aerosol transport models, J. Geophys. Res., 109, D22202, doi:10.1029/2003JD004485, 2004.

Wang, M., Ghan, S., Liu, X., L'Ecuyer, T. S., Zhang, K., Morrison, H., Ovchinnikov, M., Easter, R., Marchand, R., Chand, D., Qian, Y., and Penner, J. E.: Constraining cloud lifetime effects of aerosols using A-Train satellite observations, Geophys. Res. Lett., 39, L15709, doi:10.1029/2012GL052204, 2012.

Zhang, K., O’Donnell, D., Kazil, J., Stier, P., Kinne, S., Lohmann, U., Ferrachat, S., Croft, B., Quaas, J., Wan, H., Rast, S., and Feichter, J.: The global aerosol-climate model ECHAM-HAM, version 2: sensitivity to improvements in process representations, Atmos. Chem. Phys., 12, 8911-8949, doi:10.5194/acp-12-89112012, 2012. 